\title{
INTERNACIONALIZAÇÃO DE MICRO E PEQUENAS EMPRESAS: UMA REVISÃO SISTEMÁTICA INTEGRATIVA DOS ESTUDOS NACIONAIS
}

\section{MICRO AND SMALL ENTERPRISES INTERNATIONALISATION: AN INTEGRATIVE SYSTEMATIC REVIEW OF THE NATIONAL STUDIES}

JHENIFER ANDRESSA DA CRUZ BARRETO

Business School Unoeste

Graduanda em Administração

Oricd: https://orcid.org/0000-0001-8829-918X

E-mail: jhenifer.barreto15@hotmail.com

MARIANE APARECIDA DE BRAZ BEZERRA

Business School Unoeste

Graduanda em Administração

Oricd: https://orcid.org/0000-0003-4129-6090

E-mail: marianeap.braz@hotmail.com

\section{MARCO ANTONIO CATUSSI PASCHOALOTTO}

Professor na Business School Unoeste

Pós-Doutorando em Economia da Saúde - Nova School of Business and Economics (Portugal)

Orcid: http://orcid.org/0000-0003-2276-8531

E-mail: marcocatussi@gmail.com

Rodovia Raposo Tavares, km 572 - Bairro Limoeiro. Presidente Prudente - SP, Brasil. CEP: 19067-175

\author{
GUSTAVO YUHO ENDO \\ Professor na Business School Unoeste \\ Mestre pelo PPG em Administração - Universidade Estadual do Oeste do Paraná \\ Orcid: https://orcid.org/0000-0003-2737-6596 \\ E-mail: gustavo@unoeste.br \\ ÉRIKA MAYUMI KATO CRUZ \\ Professor da Business School Unoeste \\ Doutora em Administração - Fundação Getúlio Vargas (FGV/EAESP) \\ Orcid: https://orcid.org/0000-0003-1690-0997 \\ E-mail: erikakato@unoeste.br
}

Submissão: 03/11/2020. Revisão: 30/11/2021. Aceite: 15/01/2022. Publicação: 01/02/2022 .

DOI: http://dx.doi.org/10.22277/rgo.v15i1.5864

\section{RESUMO}

Objetivo: O presente estudo buscou analisar os trabalhos de internacionalização de Micro e Pequenas Empresas (MPEs) publicados em periódicos pertencentes à Plataforma CAPES.

Método / abordagem: Os métodos de pesquisa utilizados foram de abordagens qualitativa e quantitativa, com objetivo descritivo, por meio da revisão sistemática integrativa. Foram aplicadas 3 strings de busca para filtrar estudos voltados à temática de internacionalização de

Este é um artigo publicado em acesso aberto (Open Access) sob a licença Creative Commons Attribution, que permite uso, distribuição e reprodução em qualquer meio, sem restrições desde que o trabalho original seja corretamente citado. 
MPEs e, posteriormente, critérios de exclusão em três etapas, restando 34 artigos para análise. Para análise dos dados utilizou-se de estatísticas descritivas e demonstrações gráficas, análise de redes das Instituições de Ensino Superior (IESs) e autores, e por fim, a análise de conteúdo.

Principais resultados: Os resultados apontaram principalmente que: a maioria dos estudos são qualitativos, baseados em estudos de caso com entrevistas semiestruturadas; não há uma grande interação entre autores e IESs para o desenvolvimento de artigos, com concentração no Sudeste; e o foco majoritário dos estudos está nas vantagens e desvantagens encontrados no processo de internacionalização. Ao final, foi proposta uma agenda de pesquisa futura para a área de internacionalização de MPEs.

Contribuições metodológicas / sociais / gerenciais: Este artigo contribui, com sua agenda de pesquisa futura, ao apontar as metodologias que irão contribuir nos estudos de internacionalização de MPEs (metodológica) e as vantagens e desvantagens do processo de internacionalização das MPEs (sociais e gerenciais).

Originalidade / relevância: Por fim, este estudo é original ao analisar sistematicamente e de forma integrativa os estudos de internacionalização de MPEs, com combinação de métodos (descritivo e redes), e relevante ao se tornar uma base sólida para as novas pesquisas a serem realizadas na área.

Palavras-chave: Internacionalização. Micro e Pequenas Empresas. Revisão Sistemática Integrativa. Redes.

\section{ABSTRACT}

Purpose: The present study aims to analyze the micro and small enterprises internationalization papers published in journals from Plataforma CAPES.

Method / approach: The used research method was a descriptive approach through the integrative systematic review. Three search-strings were applied to filter studies about micro and small enterprises internationalization, and after, exclusionary criteria in 3 steps, remaining 34 papers to analyze. In addition to the data analysis, the paper has utilized descriptive statistics and graphic plots, network analysis of the universities and authors, and context analysis.

Main findings: The results have pointed out: there is no great interaction between authors and universities to develop the papers, with a concentration on the Southeast, and the majority of studies speak on the advantages and disadvantages of the internationalization process. The study proposes a future research agenda to the micro and small enterprises' internationalization area.

Methodological / social / managerial contributions: This paper contributes, with its future research agenda, by pointing out the methodologies which are going to contribute to the micro and small enterprises internationalization studies (methodological) and advantages and disadvantages in the micro and small enterprises internationalization process (social and managerial).

Originality / relevance: Therefore, this study is original when analyzing systematically and in an integrative approach the micro and small enterprises internationalization studies, with a 
Jhenifer Andressa Da Cruz Barreto, Mariane Aparecida De Braz Bezerra, Marco Antonio Catussi Paschoalotto, Gustavo Yuho Endo e Érika Mayumi Kato Cruz

methods' combination (descriptive and networks), and relevant when became a solid background to the new research in the area.

Keywords: Internationalization. Micro and Small Enterprises. Integrative Systematic Review. Networks.

\section{INTRODUÇÃO}

No âmbito dos estudos sobre internacionalização, nota-se que a compreensão do processo de internacionalização de uma organização está em constante evolução (Ruzzier, Hisrich \& Antoncic, 2006). Sabe-se que ele se inicia a partir da necessidade de crescimento e competitividade de uma empresa, além de influenciar positivamente a economia de um país (Freitas, Rupolo \& Oliveira, 2014).

A internacionalização é a expansão de bens, serviços e capitais, que provoca a concorrência entre mercados e a integração entre os sistemas econômicos (Gonçalves, 1999). Ela pode ser vista, assim, como estimuladora da globalização que, por sua vez, se trata de um fenômeno capaz de conectar todo o mundo, reduzindo fronteiras e aumentando a interdependência econômica de cada país por meio do fluxo de capital financeiro pelo mundo. Para que ocorra esse fenômeno, é de suma importância o relacionamento entre países, o que ocorre com a internacionalização. Logo, como forma de se manter competitiva, muitas empresas direcionam parte de seus negócios para o mercado internacional (Martinelli, Ventura \& Machado, 2004).

Conforme estudos feitos por Johanson \& Wiedersheim-Paul (1975), identificou-se que empresas que iniciavam com investimentos menores tinham maior sucesso comparado com aquelas que apostavam valores maiores em seu processo de internacionalização. Esse investimento desacelerado e de sucesso era dividido em etapas, tendo como iniciação a venda direta para novos mercados; posteriormente, praticavam atividades de exportação e, por último, a inserção no mercado externo. O local de inserção era definido de acordo com a proximidade cultural com o país em que a empresa já se encontrava inserida, ou seja, países que não tinham tanta diferença da cultura predominante (Eriksson et al., 1997).

Nota-se que a internacionalização de uma empresa pode ocorrer por meio de exportação, patenteamento/licenciamento, franquia, joint-venture ou investimento direto. Considerando que cada um tem seu nível de risco e retorno individual (Kotler \& Keller, 2006), conforme o estudo citado, a maioria das empresas que tiveram sucesso passaram por todos os processos ordenados, de acordo com o seu grau de risco.

Como auxílio para o entendimento do processo de internacionalização, foram desenvolvidos estudos de casos com empresas suecas dando origem ao modelo Upssala, o qual propõe que, para inibir o fracasso das empresas durante seu processo de internacionalização, é preciso ter total conhecimento sobre o comportamento do mercado em que pretende ingressar, considerando suas constantes mudanças (Silva \& Moraes, 2013).

As pequenas empresas existiram antes mesmo do surgimento das grandes organizações e, cada vez mais, vêm sendo estudadas (Leone, 1991; Zonatto et al., 2017). Elas são caracterizadas, de forma quantitativa, pelo número de colaboradores que possuem, sendo consideradas microempresas, no ramo industrial, aquelas com até 19 colaboradores, e empresas de pequeno porte as que possuem de 20 a 99 colaboradores; no setor de comércio e serviços, classificam-se como microempresas as que possuem até 9 colaboradores, e de pequeno porte as que possuem de 10 a 49 colaboradores (Sebrae, 2017). 
É importante que, quando surge a ideia de internacionalização, a empresa defina bem sua estratégia de entrada, considerando o nível de desenvolvimento econômico, bem como a evolução de indústrias ou empresas recém-inseridas no país em questão.

Porter (1989) faz uma análise, sob o ponto de vista econômico, para que as empresas se inteirem das operações que possam gerar valor ou não, podendo assim traçar melhor sua estratégia de entrada e reduzir suas chances de erros. Devido às oscilações econômicas frequentes, torna-se difícil medir essas taxas, que podem interferir no processo de internacionalização por não apresentarem resultados exatos (Kotabe \& Helsen, 1998).

O processo de internacionalização, além de ser usado como estratégia para manter a competitividade de uma empresa no mercado, também contribui para o desenvolvimento do país, considerando que países com melhores infraestruturas são escolhidos com mais frequência pelas empresas, aumentando sua capacidade de produção e distribuição de bens (Boone \& Kurtz, 1998).

No processo de internacionalização pode haver vantagens e desvantagens para as empresas que desejam ingressar nesse meio, por isso é importante agir com cautela, sempre fazendo análises do mercado onde buscam emergir. Segundo Aaker (2001), a empresa precisa decidir seu investimento, as regras e diretrizes, bem como a política que irá reger o funcionamento dela, além de seus fatores competitivos, para, então, ter sucesso em sua internacionalização. O mercado global oferece inúmeras oportunidades de crescimento e desenvolvimento, mas, para isso, a empresa precisa ter ciência de que enfrentará flutuações da moeda, leis, regulamentações, comportamentos e culturas diferentes ao de costume (Keegan, 2002).

Assim, antes de tomarem a decisão de internacionalizar, as empresas precisam analisar os aspectos sob o ponto de vista da Teoria Comportamental, que procura medir e avaliar os efeitos psicológicos, econômicos e sociais durante o processo (Silva \& Moraes, 2013). Os estudos sobre teorias do comportamento organizacional analisam questões sobre a cultura da empresa, o ambiente onde ela será inserida e outras características suas e de seus gestores (Rosa \& Rhoden, 2007).

É necessário que a empresa tenha domínio sobre todos esses fatores para manter sua sobrevivência no mercado exterior e, a partir disso, decidir quais processos e métodos serão utilizados. Para obter domínio sobre esses fatores é necessária uma pesquisa aprofundada por parte da empresa. Durante o processo, a empresa passa por fases, dentre elas o conhecimento do mercado onde ela pretende se inserir, proporcionando uma vantagem competitiva (MRE, 2011). Para facilitar essa fase, algumas empresas optam por terceirizar o serviço de consultoria como auxílio para essa pesquisa de mercado.

Dessa forma, compreende-se que o conhecimento é essencial para o desenvolvimento do processo de internacionalização e, que a falta desse conhecimento, pode retardar o processo, visto que, ao emergir em outro país, a empresa tem um objetivo que, para ser alcançado, é necessário um bom planejamento financeiro e estratégico, e ambos partem do conhecimento (Minervini, 2008). Nesse sentido, compreender as redes entre organizações, autores, instituições e empresas, pode potencializar o fluxo das informações que passam a circular em meio à sociedade, considerando principalmente o avanço tecnológico das últimas décadas, (Castells, 1999).

Nota-se, porém, que, apesar de sólida, a base teórica sobre internacionalização ainda apresenta lacunas, com destaque para a internacionalização de Micro e Pequenas Empresas (MPEs); em que um dos possíveis motivos está na dificuldade de coleta de informações concretas sobre esse tipo de organização, considerando que não há dados primários 
disponíveis (Floriani \& Fleury, 2012; Cassol et al., 2017; Canello, 2021). Diante desse cenário, as MPEs que querem aumentar sua competitividade e crescimento, por meio da expansão internacional, sofrem dificuldades, sendo a evolução da base teórica um grande avanço neste processo (Anand, 2015; Canello, 2021).

Nesse contexto, o presente artigo tem como objetivo geral analisar os estudos sobre internacionalização de MPEs encontrados em periódicos da plataforma CAPES. Como objetivos específicos, pretende-se descrever as características dos principais achados de estudos científicos sobre internacionalização de MPEs; analisar as redes de autores e universidades que compõem a população da revisão sistemática realizada; criar um quadro síntese de análise teórica com os objetivos dos artigos encontrados e sua classificação; analisar os estudos científicos de internacionalização de MPEs de forma qualitativa e integrada; e construir uma agenda de pesquisa futura para a área de internacionalização de MPEs.

Assim, este estudo justifica-se no mundo científico, ao: colaborar com a academia sobre a internacionalização de MPEs, por meio de uma Revisão Sistemática Integrativa (RSI); ampliar o olhar acadêmico sobre a internacionalização; apontar a rede de autores de universidades que estão interligadas nesta temática; e propor uma agenda de pesquisa futura para aqueles que buscam melhor compreender o assunto. Em relação à prática, a justificativa deste estudo está na apresentação e discussão do processo de internacionalização de MPEs, com suas vantagens e desvantagens, de forma a facilitar os empreendedores que queiram internacionalizar suas MPEs.

Como forma de organizar o trabalho, nessa primeira seção foi apresentada a contextualização do estudo, juntamente com os objetivos propostos e sua justificativa. Nas demais seções, respectivamente, demonstra-se o percurso metodológico utilizado na pesquisa; os resultados obtidos na pesquisa juntamente com a discussão e; por fim, as considerações finais da pesquisa, com as contribuições e limitações da pesquisa.

\section{ASPECTOS METODOLÓGICOS}

O respectivo estudo foi desenvolvido com uma abordagem qualitativa e quantitativa ao buscar significado aos dados trabalhados e explicar seus fenômenos (Triviños, 1987). Para a coleta de dados, usou-se o instrumento da pesquisa bibliográfica, que abrange toda bibliografia publicada sobre o tema a ser estudado, com a finalidade de solucionar o problema em questão (Lakatos \& Marconi, 2001). O tipo de pesquisa utilizada foi a descritiva. A pesquisa descritiva busca organizar os dados de forma que estes formem uma nova pesquisa explicativa, fundamentada na experimentação (Cooper \& Schindler, 2006).

Para a coleta e análise de dados foi utilizada a Revisão Sistemática Integrativa (RSI) que consiste em um tipo de revisão de dados coletados de forma clara e objetiva sob um nicho mais específico (Greenhalgh, 1997, p. 672), enquanto a forma integrativa é mais abrangente e obtém novas informações sobre o assunto abordado (Silva, Paschoalotto \& Endo, 2020).

Seguindo a sistematização dessa metodologia, a figura 1 demonstra o protocolo utilizado para a seleção dos artigos usados no estudo. 
Internacionalização de micro e pequenas empresas:

uma revisão sistemática integrativa dos estudos nacionais

Figura 1

Processo de protocolo utilizado para seleção de artigos

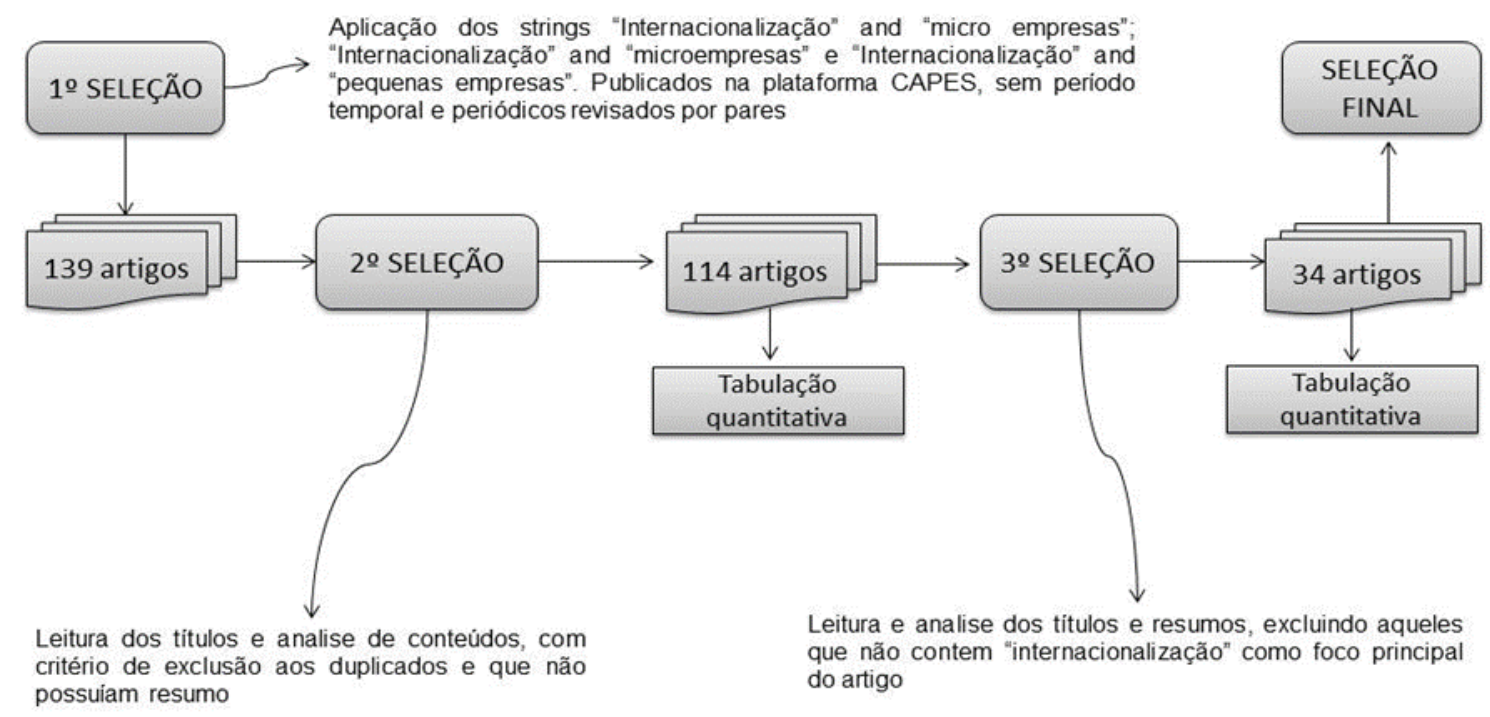

No dia 18 de outubro de 2019, por meio de busca na plataforma CAPES, utilizando as strings: "Internacionalização" AND "Pequenas Empresas", "Internacionalização" AND "microempresas" e "Internacionalização" AND "microempresas", foram encontrados 139 resultados a respeito do tema, sem período temporal.

Com esses 139 artigos foi construída uma planilha no Microsoft Excel organizada por títulos, resumos, revista cientifica onde o artigo foi publicado e Qualis, tipo de pesquisa do artigo, método de coleta de dados e ano de publicação, organização nomeada de tabulação quantitativa.

$\mathrm{Na}$ planilha foi aplicado o segundo filtro, por meio da leitura dos títulos, sendo eliminados 25 artigos, considerando os que possuíam títulos duplicados, algumas vezes por se tratar do mesmo artigo, mas em linguagens ou formatação diferentes, e os que não tinham resumo. Também foram retirados 80 artigos pelo fato de possuírem a "internacionalização" como um fator adicional e não principal aos estudos, sendo assim, sem relevância para a presente análise. Finalizando com 34 artigos que foram atribuídos à planilha, revistos através da tabulação quantitativa e utilizados para a apresentação e discussão dos resultados.

Para os objetivos estabelecidos nessa pesquisa, pode-se utilizar das seguintes ferramentas para análise dos dados:

1) descrever as características dos principais achados de estudos científicos sobre internacionalização de MPEs: utilizou-se de estatísticas descritivas e demonstrações gráficas quanto ao tipo de pesquisa (abordagem); tipo de pesquisa (finalidade); método de coleta de dados; qualis da revista científica, classificação da temática e distribuição temporal das publicações (Cooper \& Schindler, 2006; Silva, Paschoalotto \& Endo, 2020);

2) analisar as redes de autores e universidades que compõem a população da revisão sistemática realizada: foram criadas redes dos autores e das universidades para análise de suas conexões nas publicações destacadas a partir da utilização do Software UCINET program (Souza \& Quandt, 2008);

3) criar um quadro síntese de análise teórica com os objetivos dos artigos encontrados e sua classificação, analisar os estudos científicos de internacionalização de MPEs de forma qualitativa e integrada e construir uma agenda de pesquisa futura para a área 
de internacionalização de MPEs: para o desenvolvimento dos 3 objetivos apontados anteriormente, utilizou-se da análise de conteúdo da Bardin (2011), seguindo suas 3 etapas (pré-análise, exploração do material e tratamento dos resultados, inferência e interpretação), como forma de realizar uma análise profunda e categorizada das características qualitativas dos achados e estudos, os quais podem ser observados nos resultados e discussões.

\section{APRESENTAÇÃO DOS RESULTADOS}

Para um melhor entendimento deste artigo, os resultados e discussões foram divididos em seções, que são: análise descritiva da revisão sistemática; análise teórica dos artigos selecionados; análise qualitativa dos artigos e discussão e proposta de agenda futura de pesquisa.

\subsection{Apresentação quantitativa da revisão sistemática}

Com base nos dados e informações adquiridos por meio da RSI, foi possível notar que grande parte dos estudos sobre internacionalização de MPEs publicados em periódicos encontrados na Plataforma CAPES tem como objetivo principal analisar casos de empresas específicas (12 artigos), seguido por identificar as vantagens e desvantagens de internacionalizar (11 artigos), analisar o processo de internacionalização (7 artigos) e verificar a revisão teórica de artigos publicados em redes especificas (4 artigos). Assim sendo, os principais temas abordados são os casos de empresas (12), vantagens e desvantagens (11), processo de internacionalização (07) e revisão teórica (04).

Dos trinta e quatro artigos analisados, nove foram publicados em revistas com Qualis A2, outros onze em revistas de Qualis B1, treze em revistas com Qualis B2 e apenas um artigo que não possuía Qualis na área da Administração. Os Qualis foram definidos por meio da Plataforma SUCUPIRA, com área de avaliação em Administração Pública e de Empresas, Ciências Contábeis e Turismo, em classificação de periódicos quadriênios 2013-2016.

As principais abordagens presentes nos artigos analisados foram descritivas (15) e exploratórias (15); também houve artigos com abordagem explicativa (01) e alguns que conciliaram a abordagem descritiva e exploratória (03), combinando a utilização de ambas no mesmo artigo.

Quanto a finalidade do tipo de pesquisa, a predominância entre os artigos foi a pesquisa qualitativa (23); os demais fizeram uso de pesquisa quantitativa (08) e métodos mistos (03) - fazendo a junção da finalidade qualitativa e quantitativa.

A coleta de dados dos artigos analisados, na maioria, ocorreu por meio de entrevistas (21); as demais foram utilizadas revisão bibliográfica (07), survey (03), questionário eletrônico (02) e levantamento documental (01).

A figura 2 contribui para a melhor visualização das informações levantadas, como segue na sequência. Dentre os estudos encontrados, nos anos de 2008 e 2010 houve três publicações para cada respectivo ano, no intervalo (2009) não houve nenhuma. Em 2011 apenas um artigo publicado. A partir de 2012 observou-se um aumento de publicações, sendo quatro em 2012, cinco em 2013 e quatro novamente em 2014. Em 2015 houve três publicações, e em 2016 novamente um aumento sendo de quatro artigos publicados. 
Internacionalização de micro e pequenas empresas: uma revisão sistemática integrativa dos estudos nacionais

Figura 2

Classificações dos artigos pesquisados

Tipo de pesquisa (abordagem)

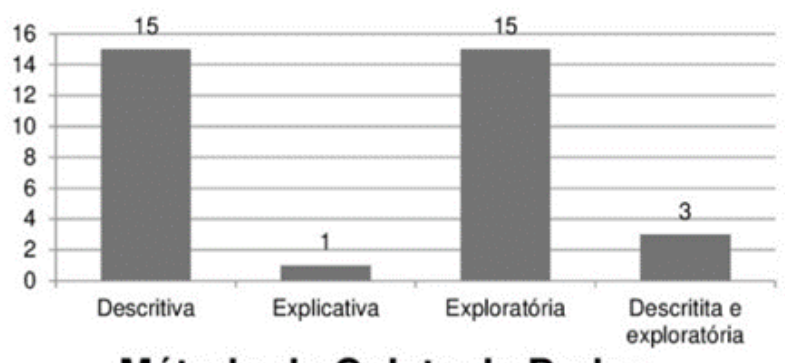

Método de Coleta de Dados

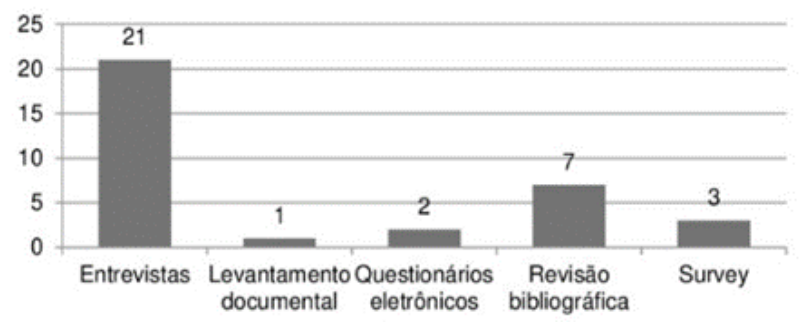

Tipo de pesquisa (finalidade)

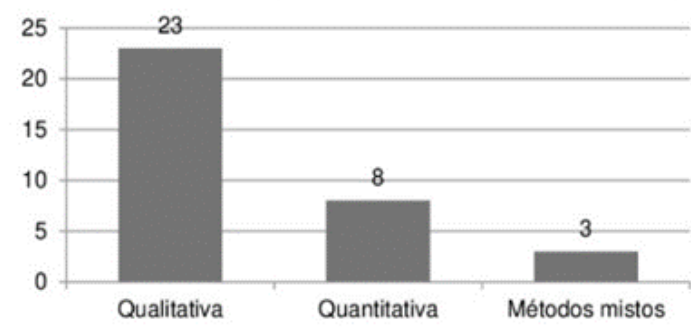

Qualis da Revista Científica

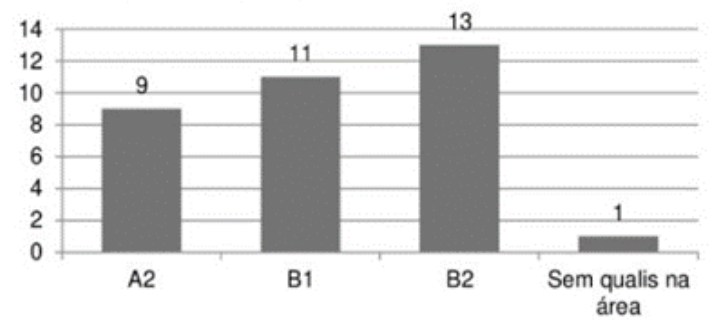

Classificação da temática

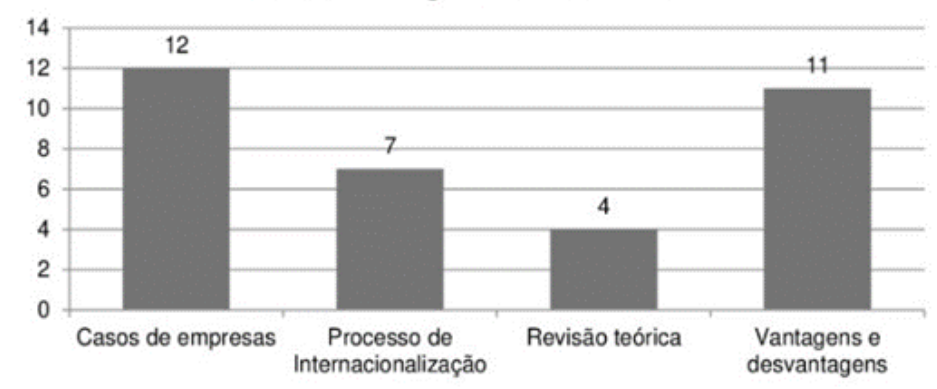

No ano de 2017 encontraram-se três artigos publicados e em 2018 houve uma queda que resultou em duas publicações para seu respectivo ano e para 2019 (Figura 3). Vale ressaltar que na pesquisa não foi aplicado período temporal nos estudos publicados na Plataforma CAPES.

Figura 3

Artigos encontrados organizados por ano

\section{Ano de Publicação}

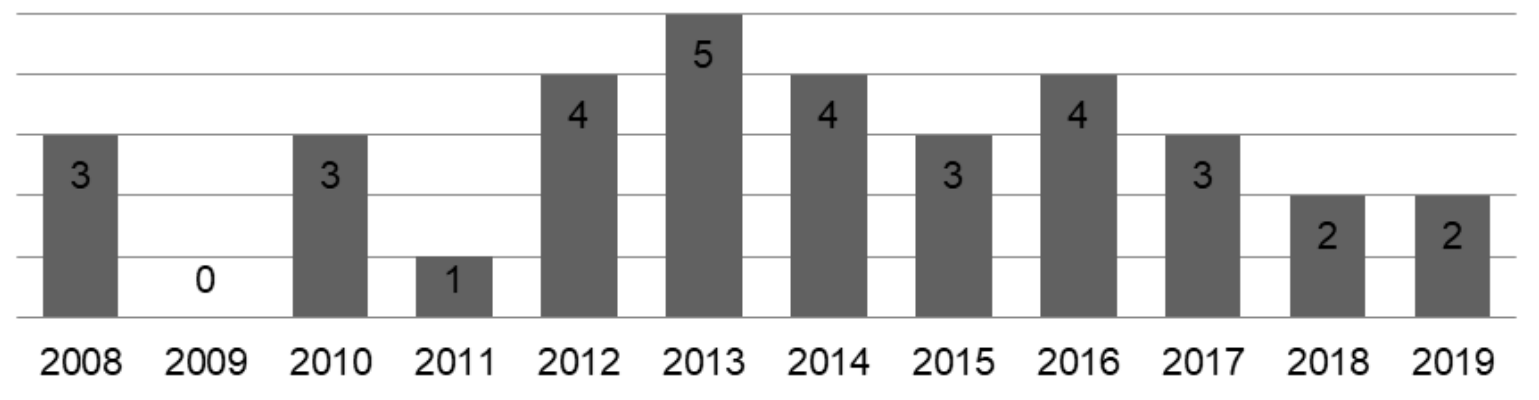


Com relação aos artigos publicados em 2008, um é sobre casos de empresas (Mello \& Rocha, 2008), um sobre vantagens e desvantagens (Lima et al., 2008) e uma pesquisa sobre revisão teórica (Jabbour, Santos \& Barbieri, 2008). Em 2010, resultaram três artigos, sendo dois deles sobre casos de empresas (Cassanego Jr. \& Ribeiro, 2010; Rocha et al., 2010) e um sobre vantagens e desvantagens (Garcia, Lima \& Carvalho, 2010). Em 2011 houve um estudo sobre vantagens e desvantagens (Lima \& Carvalho, 2011). Em 2012, foram dois estudos sobre vantagens e desvantagens (Floriani \& Fleury, 2012; Silveira et al., 2012) e dois estudos sobre casos de empresas (Ribeiro, Oliveira Jr \& Borini, 2012; Zen, 2012).

No ano de 2013 foram publicados seis estudos, sendo um deles sobre o processo de internacionalização (Fiates et al., 2013), um sobre revisão teórica (Barki, Botelho \& Parente, 2013), um sobre casos de empresas (Silva \& Moraes, 2013) e dois sobre vantagens e desvantagens (Krakawer, Jussani \& Vasconcellos, 2013, Zapata \& Barrientos, 2013). Em 2014, foram quatro estudos, sendo dois deles sobre o processo de internacionalização (Vianna, Melo \& Ryngelblum, 2014; Matta \& Mello, 2014), um sobre casos de empresas (Freitas, Rupolo \& Oliveira, 2014) e um sobre vantagens e desvantagens (Leite \& Moraes, 2014).

Em 2015 a pesquisa apontou três estudos, sendo dois sobre casos de empresas (DalSato et al., 2015; Porto \& Mello, 2015) e um sobre vantagens e desvantagens (Leite \& Moraes, 2015). Em 2016, houve um estudo sobre processo de internacionalização (Domingues, Muritiba, P. \& Muritiba, S., 2016), dois sobre casos de empresa (Santos, 2016; Sarmento, Carvalho \& Dib, 2016) e um sobre revisão teórica (Ribeiro, 2016). Em 2017 houve um artigo sobre vantagens e desvantagens (Lara \& Verdu, 2017) e dois estudos sobre processo de internacionalização (Cislaghi, Fernandes \& Wegner, 2017; Gatti Jr \& Marietto, 2017). Posteriormente, em 2018 foram dois artigos encontrados, sendo um sobre revisão teórica (Araújo, Silva \& Cardoso, 2018) e um sobre o processo de internacionalização (Rosa, Mello \& Ferreira, 2018). 2019 resultou em dois artigos, um sobre casos de empresas (Herranz, \& Machado, 2019) e outro sobre vantagens e desvantagens (Bellucci, Lavarda \& Roczanski, 2019).

\subsection{Análise teórica}

Para um melhor entendimento sobre os avanços dos artigos coletados neste estudo, foi elaborado um quadro síntese de análise teórica dividido de forma alfabética e classificado segundo as áreas temáticas.

Tabela 1

Quadro síntese de análise teórica dos artigos coletados na revisão sistemática

\begin{tabular}{c|l|c}
\hline Estudos & Objetivos & Classificação \\
\hline $\begin{array}{c}\text { Mello \& Rocha } \\
\text { (2008) }\end{array}$ & $\begin{array}{l}\text { Analisar a utilização de um diferencial voltado à um segmento } \\
\text { específico como estratégia e como isso contribui para o } \\
\text { desenvolvimento internacional de uma pequena empresa. }\end{array}$ & Casos de empresas \\
\hline $\begin{array}{c}\text { Cassanego Jr. \& } \\
\text { Ribeiro (2010) }\end{array}$ & $\begin{array}{l}\text { Identificar o comportamento estratégico das organizações no } \\
\text { campo do turismo da Fronteira da Paz. }\end{array}$ & Casos de empresas \\
\hline $\begin{array}{c}\text { Rocha et al. } \\
\text { (2010) }\end{array}$ & $\begin{array}{l}\text { Analisar como a empresa pode aumentar suas atividades no } \\
\text { mercado nacional e como isso pode ajudar em seu processo de } \\
\text { internacionalização. }\end{array}$ & Casos de empresas \\
\hline $\begin{array}{c}\text { Ribeiro, Oliveira } \\
\text { Jr \& Borini } \\
\text { (2012) }\end{array}$ & $\begin{array}{l}\text { Analisar o grau de interferência e a relação do ambiente externo, } \\
\text { fatores organizacionais e empreendedor para a empresa em seu } \\
\text { país de origem. E como isso pode acelerar o processo de empresas } \\
\text { de base tecnológicas (EBT's). }\end{array}$ & Casos de empresas \\
\hline
\end{tabular}


Internacionalização de micro e pequenas empresas:

uma revisão sistemática integrativa dos estudos nacionais

\begin{tabular}{|c|c|c|}
\hline Zen (2012) & $\begin{array}{l}\text { Analisar por meio de estudo de caso a influência do processo de } \\
\text { internacionalização sobre o desenvolvimento de recursos } \\
\text { estratégicos. }\end{array}$ & Casos de empresas \\
\hline $\begin{array}{l}\text { Silva \& Moraes } \\
\qquad(2013)\end{array}$ & $\begin{array}{l}\text { Analisar a evolução dentro de um período temporal do Modelo } \\
\text { Upssala, por meio da observação de empresas em processos de } \\
\text { internacionalização. }\end{array}$ & Casos de empresas \\
\hline $\begin{array}{l}\text { Freitas, Rupolo } \\
\text { \& Oliveira } \\
(2014)\end{array}$ & $\begin{array}{l}\text { Analisar por meio de estudo de caso a internacionalização de uma } \\
\text { empresa como fator estratégico e suas características. }\end{array}$ & Casos de empresas \\
\hline $\begin{array}{l}\text { Dal-Sato et al. } \\
\qquad(2015)\end{array}$ & $\begin{array}{l}\text { Analisar por meio de teorias da abordagem comportamental o } \\
\text { processo de internacionalização de empresas do segmento de } \\
\text { software. }\end{array}$ & Cas \\
\hline $\begin{array}{r}\text { Porto } \\
(2\end{array}$ & $\begin{array}{l}\text { Compreender a importância do empreendedor no processo de } \\
\text { internacionalização através da teoria Effectuation. }\end{array}$ & Casos de empresas \\
\hline Santos (2016) & $\begin{array}{l}\text { Analisar estratégias que fortaleça a vantagem competitiva por meio } \\
\text { da internacionalização dos grupos Mexichem e Tigre. }\end{array}$ & Casos de en \\
\hline $\begin{array}{l}\text { Sarmento, } \\
\text { Carvalho \& Dib } \\
\text { (2016) }\end{array}$ & $\begin{array}{l}\text { Compreender como as aceleradoras tornam mais rápido a inserção } \\
\text { de startups no mercado internacional. }\end{array}$ & Casos de \\
\hline Herr & $\begin{array}{l}\text { Conhecer os propulsores da internacionalização em pequenas } \\
\text { empresas de software. }\end{array}$ & Casos d \\
\hline $\begin{array}{l}\text { Fiates et al. } \\
\qquad(2013)\end{array}$ & $\begin{array}{l}\text { Analisar os fatores que influenciam o processo de } \\
\text { internacionalização de pequenas e medias empresas de base } \\
\text { tecnológica, e identificar a influência e importância das incubadoras } \\
\text { nesse processo. }\end{array}$ & $\begin{array}{r}\text { Processc } \\
\text { internacion }\end{array}$ \\
\hline $\begin{array}{l}\text { Matta \& Mello } \\
\qquad(2014)\end{array}$ & $\begin{array}{l}\text { Analisar os fatores que desencadeiam o processo de } \\
\text { internacionalização em empresas brasileiras de software de } \\
\text { segurança. }\end{array}$ & $\begin{array}{r}\text { Process } \\
\text { internacion }\end{array}$ \\
\hline $\begin{array}{r}\text { Vianna } \\
\text { Ryng } \\
(2 \\
\end{array}$ & $\begin{array}{l}\text { Compreender como ocorreu o processo decisório referente ao } \\
\text { processo de internacionalização de franquias brasileiras. }\end{array}$ & $\begin{array}{l}\text { Processo de } \\
\text { internacionalização }\end{array}$ \\
\hline $\begin{array}{l}\text { Domingues, } \\
\text { Muritiba, P. \& } \\
\text { Muritiba, S. } \\
\text { (2016) }\end{array}$ & $\begin{array}{l}\text { Classificar a governança corporativa das PME's com o uso de um } \\
\text { modelo específico, e investigar a relação entre governo e a } \\
\text { internacionalização nas PME's do Brasil. }\end{array}$ & $\begin{array}{l}\text { Processo de } \\
\text { internacionalização }\end{array}$ \\
\hline $\begin{array}{l}\text { Cislaghi, } \\
\text { Fernandes \& } \\
\text { Wegner (2017) }\end{array}$ & $\begin{array}{l}\text { de que forma o processo de internacionalização contribui } \\
\text { ransformação das capacidades dinâmicas de uma pequena } \\
\text { que atua no ramo de orgânicos. }\end{array}$ & $\begin{array}{l}\text { Processo de } \\
\text { internacionalização }\end{array}$ \\
\hline $\begin{array}{l}\text { Gatti Jr \& } \\
\text { Marietto (2017) }\end{array}$ & $\begin{array}{l}\text { Demonstrar por meio de um estudo como uma pequena empresa } \\
\text { brasileira do ramo de animação produziu e comercializou nacional e } \\
\text { internacionalmente seu produto, uma serie de anime infantil. }\end{array}$ & $\begin{array}{l}\text { Processo de } \\
\text { internacionalização }\end{array}$ \\
\hline $\begin{array}{l}\text { Rosa, Mello \& } \\
\text { Ferreira (2018) }\end{array}$ & $\begin{array}{l}\text { Analisar e identificar possíveis relações entre o crescimento } \\
\text { acelerado das empresas denominadas Scale-Up e o processo de } \\
\text { internacionalização das mesmas. }\end{array}$ & $\begin{array}{l}\text { Processo de } \\
\text { internacionalização }\end{array}$ \\
\hline $\begin{array}{l}\text { Jabbour, Santos } \\
\text { \& Barbieri } \\
(2008)\end{array}$ & $\begin{array}{l}\text { Analisar periódicos com base nos parâmetros: aumento da } \\
\text { produção; origem de autoria; perfil metodológico; conteúdo e } \\
\text { abrangência das análises; e o grau internacional das referências. }\end{array}$ & Revisão teórica \\
\hline $\begin{array}{l}\text { Barki, Botelho \& } \\
\text { Parente (2013) }\end{array}$ & $\begin{array}{l}\text { Descrever as principais temáticas abordadas no Congresso Latino- } \\
\text { Americano de Varejo (CLAV) até o ano de } 2012 .\end{array}$ & Revisão teórica \\
\hline Ribeiro (2016) & $\begin{array}{l}\text { Explorar os estudos acadêmicos referentes a internacionalização, } \\
\text { durante um período temporal, em determinadas revistas. }\end{array}$ & Revisão teórica \\
\hline $\begin{array}{l}\text { Araújo, Silva \& } \\
\text { Cardoso (2018) }\end{array}$ & $\begin{array}{l}\text { Analisar as abordagens e contribuições de estudos publicados nas } \\
\text { principais revistas brasileiras referentes à gestão de pequenas } \\
\text { empresas. }\end{array}$ & Revisão teórica \\
\hline
\end{tabular}


Jhenifer Andressa Da Cruz Barreto, Mariane Aparecida De Braz Bezerra, Marco Antonio Catussi Paschoalotto, Gustavo Yuho Endo e Érika Mayumi Kato Cruz

\begin{tabular}{|c|c|c|}
\hline $\begin{array}{l}\text { Lima et al. } \\
\qquad(2008)\end{array}$ & $\begin{array}{l}\text { Demonstrar o quão importante é o uso de alianças do mesmo } \\
\text { segmento ou similares, para a exportação em conjunto de produtos } \\
\text { ou serviços de micro e pequenas empresas. }\end{array}$ & $\begin{array}{l}\text { Vantagens e } \\
\text { desvantagens }\end{array}$ \\
\hline $\begin{array}{l}\text { Garcia, Lima \& } \\
\text { Carvalho (2010) }\end{array}$ & $\begin{array}{l}\text { Analisar o consórcio como forma de associação de empresas com } \\
\text { vistas na internacionalização. }\end{array}$ & $\begin{array}{l}\text { Vantagens e } \\
\text { desvantagens }\end{array}$ \\
\hline $\begin{array}{l}\text { Lima \& Carvalho } \\
\qquad(2011)\end{array}$ & $\begin{array}{l}\text { Identificar fatores interligados do processo de internacionalização } \\
\text { que levam micro e pequenas empresas se inserirem no mercado } \\
\text { internacional. }\end{array}$ & $\begin{array}{l}\text { Vantagens e } \\
\text { desvantagens }\end{array}$ \\
\hline $\begin{array}{l}\text { Floriani \& Fleury } \\
\qquad(2012)\end{array}$ & $\begin{array}{l}\text { Analisar correlações entre o índice financeiro, o desenvolvimento de } \\
\text { práticas internacionais e o grau internacional de pequenas e medias } \\
\text { empresas brasileiras. }\end{array}$ & $\begin{array}{l}\text { Vantagens e } \\
\text { desvantagens }\end{array}$ \\
\hline $\begin{array}{l}\text { Silveira et al. } \\
\qquad(2012)\end{array}$ & $\begin{array}{l}\text { Analisar o processo de verticalização e desverticalização com foco } \\
\text { no uso da inovação aberta e as vantagens que isso traz para a } \\
\text { empresa. }\end{array}$ & $\begin{array}{l}\text { Vantagens e } \\
\text { desvantagens }\end{array}$ \\
\hline $\begin{array}{c}\text { Krakawer, } \\
\text { Jussani \& } \\
\text { Vasconcellos } \\
\text { (2013) }\end{array}$ & $\begin{array}{l}\text { Entender as vantagens que alianças estratégicas podem trazer para } \\
\text { o processo de internacionalização de pequenas e medias empresas. }\end{array}$ & $\begin{array}{l}\text { Vantagens e } \\
\text { desvantagens }\end{array}$ \\
\hline $\begin{array}{l}\text { Zapata \& } \\
\text { Barrientos } \\
(2013)\end{array}$ & $\begin{array}{l}\text { Analisar os principais desafios da gestão entre culturas no processo } \\
\text { de internacionalização de microempresas de Medellín, Colômbia. }\end{array}$ & $\begin{array}{l}\text { Vantagens e } \\
\text { desvantagens }\end{array}$ \\
\hline $\begin{array}{l}\text { Leite \& Moraes } \\
(2014)\end{array}$ & $\begin{array}{l}\text { Analisar os maiores riscos que um empreendedor enfrente no } \\
\text { processo de internacionalização. }\end{array}$ & $\begin{array}{l}\text { Vantagens e } \\
\text { desvantagens }\end{array}$ \\
\hline $\begin{array}{l}\text { Leite \& Moraes } \\
\text { (2015) }\end{array}$ & $\begin{array}{l}\text { Analisar através de vários estudos, a capacidade de pequenas e } \\
\text { medias empresas inovarem seus produtos ou serviços a nível } \\
\text { internacional. }\end{array}$ & $\begin{array}{l}\text { Vantagens e } \\
\text { desvantagens }\end{array}$ \\
\hline $\begin{array}{l}\text { Lara \& Verdu, } \\
\qquad(2017)\end{array}$ & $\begin{array}{l}\text { Identificar os fatores motivacionais, facilitadores e as dificuldades } \\
\text { do processo de internacionalização através do estudo de caso de } \\
\text { duas empresas que fizeram o processo. }\end{array}$ & $\begin{array}{l}\text { Vantagens e } \\
\text { desvantagens }\end{array}$ \\
\hline $\begin{array}{l}\text { Bellucci, } \\
\text { Lavarda \& } \\
\text { Roczanski } \\
\text { (2019) }\end{array}$ & $\begin{array}{l}\text { Identificar e entender como os níveis organizacionais se integram } \\
\text { quando as empresas realizam estrategicamente a pesquisa de } \\
\text { mercado para o processo de internacionalização. }\end{array}$ & $\begin{array}{l}\text { Vantagens e } \\
\text { desvantagens }\end{array}$ \\
\hline
\end{tabular}

Com essa perspectiva, e após a análise descritiva e teórica, pode-se apontar que: 1) grande parte dos estudos aqui elencados seguem a linha de "casos de empresas", tendência essa vista também mais recentemente (Anand, 2015; Kazungu, 2020); 2) há necessidade de se compreender o processo de internacionalização em diferentes perspectivas (Anand, 2015; Canello, 2021); 3) há abertura para novas estudos sobre vantagens e desvantagens da internacionalização para MPEs (Kubíčková, Votoupalová \& Toulová, 2014; Canello, 2021); e 4) existem revisões teóricas, mas muito específicas e não diretamente vinculadas à internacionalização de MPEs.

\subsection{Rede de autores e universidades}

Mesmo com o reconhecimento da importância de haver uma relação entre autores e instituições que compartilham estudos da mesma temática, os artigos aqui abordados resultaram redes pouco abertas de cooperação, o que representa uma baixa conexão entre autores e universidades distintas, indo contrariamente ao relatado por Castells (1999) em relação à potencialidade das redes. 
Figura 4

Rede de relacionamento entre os autores

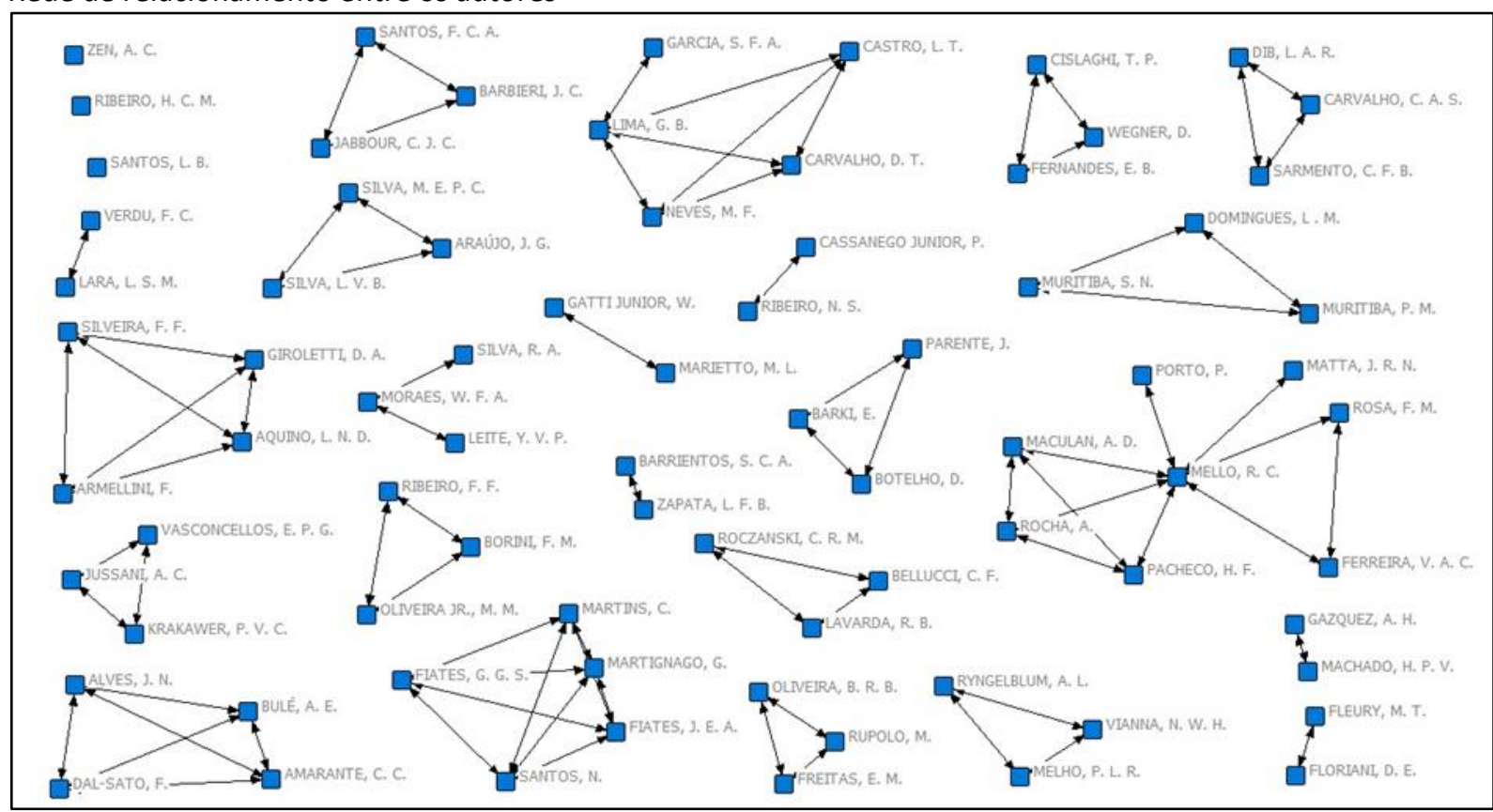

Na figura 4, alguns autores como Mello, R. C. tem uma rede pouco aberta, sendo esse o autor com maior número de conexões, pela contribuição em artigos com classificações distintas, mas que abordam a mesma temática, como o estudo "Ivia: crescimento e internacionalização" que é classificado como casos de empresa, desenvolvido por Mello, R. C. junto à Rocha, A.; Maculan, A. D. e Pacheco, H. F., outro estudo fruto da parceria de Mello \& Rocha, foi "Casos de Ensino em Administração - Constança Basto" que possui a mesma classificação anterior de casos de empresas, o mesmo acontece com Porto, P. que juntamente com Mello, R. C. desenvolveram um estudo de casos de empresas voltado para o “Empreendedorismo internacional e Effectuation: O caso do Café Yaguara Ecológico". Já Rosa, F. M. e Ferreira, V. A. C. em união com Mello, R. C. produziram um estudo de classificação de Processo de Internacionalização sendo "O fenômeno da Internacionalização e as Empresas Scale-Up: Uma revisão Sistemática da Literatura", e como conclusão dessa rede, Mello \& Matta também contemplaram a classificação de Processo de Internacionalização com o artigo "A internacionalização de uma empresa Brasileira de software de segurança a luz das teorias de redes e effectuation".

Também foi observada a presença de outras duas redes menores, sendo uma interligada por Lima \& Carvalho que juntos desenvolveram o estudo "Internacionalização de empresas em clusters industriais: um estudo aplicado no Polo Médico-HospitalarOdontológico de Ribeirão Preto - SP" de classificação Vantagens e desvantagens, e também possuem relacionamento com outros autores, sendo uma outra conexão com Garcia, S. F. A. com o estudo "Redes interorganizacionais de cooperação para a internacionalização" que também pertence a uma classificação de Vantagens e desvantagens, o mesmo acontece com Neves, M. F. e Castro, L. T. com o artigo "Consórcio de exportação como alternativa de pequenas e médias empresas: um estudo de caso na cadeia têxtil" que possui participação de Lima \& Carvalho e uma classificação de Vantagens e desvantagens no processo de internacionalização. Outra rede semelhante é formada por Moraes, W. F. A. que se conecta duas vezes com Leite, Y. V. P., desenvolvendo os estudos "A capacidade de inovar no empreendedorismo internacional" e "Facetas do risco no empreendedorismo internacional", 
ambos com a classificação de Vantagens e desvantagens, já com SILVA, R. A., o estudo "A evolução do modelo de Upssala a luz da abordagem dos sistemas adaptativos complexos (Ensayo)" possui uma classificação de casos de empresas.

Figura 5

Rede de universidades

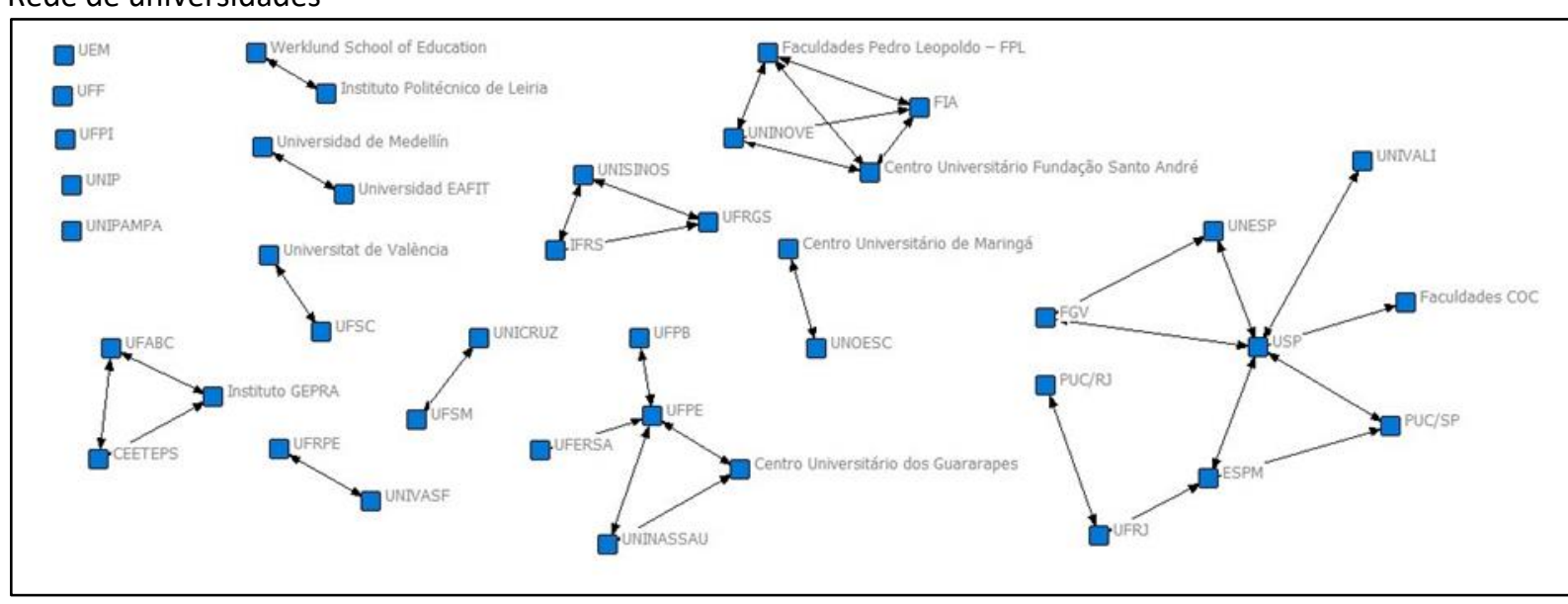

A figura 5 demonstra a rede de universidades, as quais possuem ligações diretas e fechadas, ou seja, os autores são interligados a uma IES e raramente se relacionam com outra rede de ensino para compartilhamento e expansão de conhecimentos sobre a temática de internacionalização de microempresas e pequenas empresas, contrapondo as vantagens apontadas por Castells (1999).

As instituições com maior relacionamento entre os autores são a Universidade de São Paulo - USP e a Universidade Federal do Rio de Janeiro - UFRJ como centros regionais base, de forma que, se caracterizam como as IES que mais possuem artigos publicados relacionados à internacionalização de micro e pequenas empresas.

$\mathrm{Na}$ rede que tem a USP como centro regional base, os artigos que promovem esse relacionamento são "Gestão ambiental: um levantamento da produção científica brasileira divulgada em periódicos da Área de administração entre 1996 e 2005" feito por um autor da USP, um da UNESP e um da Fundação Getúlio Vargas - FGV, também o estudo "Consórcio de exportação como alternativa de pequenas e médias empresas: um estudo da cadeia têxtil" que é fruto da parceria de três autores da USP e um autor da Faculdades COC - SP, outra conexão que compõe essa rede é formada por um autor da USP, um autor da Pontifícia Universidade Católica - PUC/SP e um autor da Escola Superior de Propaganda e Marketing ESPM/SP com o estudo "Internacionalização acelerada de empresas de base tecnológica: o caso das born globais Brasileiras", há também um o artigo "O efeito do grau de internacionalização nas competências internacionais e no desempenho financeiro da PME brasileira" feito por um autor da USP e um autor da Universidade do Vale do Itajaí - UNIVALI, as demais ocorrências que compõe essa rede é somente entre autores da USP não acontecendo a troca de conhecimento entre IES's.

Na rede com a UFRJ como centro regional base, as conexões com PUC/RJ são com os artigos "Empreendedorismo internacional e Effectuation: O caso da café Yaguara Ecológico" e "Ivia: crescimento e internacionalização", as demais conexões são entre os autores da UFRJ com os artigos "Casos de ensino em administração - Constança Basto", "Effectuation e a influência das redes sociais em internacionalização de startups em aceleradoras" e "O 
Internacionalização de micro e pequenas empresas:

uma revisão sistemática integrativa dos estudos nacionais

fenômeno da internacionalização e as empresas scale-up: Uma revisão sistemática da literatura".

Com um menor número de publicações, mas com uma capacidade de centralizar conexões, vale também destacar a Universidade Federal de Pernambuco - UFPE, sendo um ponto de referência no Nordeste brasileiro, que possui conexão com a Universidade Federal Rural do Semi-Árido - UFERSA por intermédio dos artigos "A capacidade de inovar no empreendedorismo internacional" e "Facetas de risco no empreendedorismo internacional" ambas com os mesmos autores, depois há uma conexão com a Universidade Federal de Paraíba - UFPB com o artigo "A evolução do modelo de Upssala a luz da abordagem dos sistemas adaptativos complexos. (Ensayo)", e para fechar essa rede há também um relacionamento entre a UFPE, UNINASSAU e o Centro Universitário dos Guararapes por meio do estudo "Pequenas empresas e as práticas gerenciais: contribuições a partir da observação das revistas brasileiras".

Através dessa análise de redes observa-se que uma grande gama dos artigos destacados são os mesmos, participando de redes abertas limitadas tanto dos autores, quanto das IES. Por fim, é importante salientar a falta de integração entre as diferentes regiões do Brasil para realização de publicações em conjunto, como pode ser observado nas redes formadas: a maior rede relativa às instituições do Sudeste, e as demais com instituições basicamente do seu próprio Estado.

\subsection{Apresentação qualitativa da revisão sistemática}

É notório que as pesquisas sobre internacionalização de MPEs como um todo têm maior foco nas vantagens e desvantagens que esse processo pode trazer, apresentando as barreiras e dificuldades que organizações enfrentam ao emergirem em um mercado internacional, além de destacar a falta de base literária referente ao tema (Floriani \& Fleury, 2012).

Nota-se também que as empresas veem esse processo como uma estratégia para se manterem eficazes em um mercado que exige competitividade (Cislaghi, Fernandes \& Wegner, 2017; Rosa, Mello \& Ferreira, 2018; Fiates et al., 2013; Vianna, Melo \& Ryngelblum, 2014).

Dentre os estudos analisados sobre a internacionalização dessas empresas, observouse que estes estão voltados para melhor compreender as vantagens e desvantagens do processo de internacionalizar, dentre elas a vantagem competitiva como um fator positivo (Zapata \& Barrientos, 2013; Lara \& Verdu, 2017; Lima \& Carvalho, 2011; Krakawer, Jussani \& Vasconcellos, 2013; Floriani \& Fleury, 2012; Leite \& Moraes, 2015; Leite \& Moraes, 2014).

Os estudos analisados expõem que um processo de internacionalização envolve diversos aspectos, como o perfil empreendedor presente na gestão da empresa, a força da cultura organizacional (Cislaghi, Fernandes \& Wegner, 2017), os objetivos a serem alcançados e a utilização da internacionalização como estratégia. Os fatores internos da empresa têm tanta influência, quanto os externos.

Algumas empresas têm um resultado satisfatório em sua internacionalização, que acontece rapidamente, essas são chamadas de empresas aceleradoras (Sarmento, Carvalho \& Dib, 2016) e são caracterizadas por serem totalmente preparadas para fatores internos e externos, além de terem um perfil empreendedor à frente do processo (Ribeiro, Oliveira Jr \& Borini, 2012).

Por outro lado, há empresas que lidam com o fracasso em sua internacionalização, o qual pode estar ligado a fatores como a falta de conhecimento interno sobre as práticas de 
controle e sistematização da empresa (Araújo, Silva \& Cardoso, 2018) e outras falham em seu processo pela falta uma base sólida de informação que possa auxiliar a internacionalização (Floriani \& Fleury, 2012).

\subsection{Proposta de Agenda Futura de Pesquisa}

Devido à falta de base teórica sobre a temática "internacionalização de MPEs", e a partir dos resultados trazidos acima pela análise descritiva, análise teórica, análise de redes e análise qualitativa, este estudo apresenta uma proposta de agenda futura de pesquisa correspondente ao tema, conforme direções apontadas:

1) Pesquisas com finalidade quantitativa e foco na temática de internacionalização de MPEs ou outro tema semelhante, possibilitando generalização estatística, por meio de coleta de dados estruturada com base em estatísticas (Araújo, Silva \& Cardoso, 2018), resultando em maior confiabilidade aos dados coletados.

2) Elaboração de um manual consolidado de estudos com as variáveis que influenciam a internacionalização de MPEs, com base sólida de informações que possibilitem as empresas interessadas terem um conhecimento mais profundo sobre o assunto, auxiliando-as nesse processo (Krakawer, Jussani \& Vasconcellos, 2013; Silveira et al., 2012).

3) Padronização dos conteúdos relacionados ao processo de internacionalização de MPEs, de forma que possa haver uma melhor conciliação entre a prática e a teoria (Ribeiro, 2016), facilitando assim, a interpretação de pesquisas que abordem essa temática.

4) Estudos antropológicos, como a etnografia, o que permitiria a identificação de outros aspectos fundamentais que este tipo de estudo permite (Floriani \& Fleury, 2012) e aprofundamento teórico dos aspectos presentes em um processo de internacionalização.

5) Projetos de pesquisa e estudos futuros que conectem em uma rede aberta de relacionamento entre os autores de diferentes regiões e IES, possibilitando um maior fluxo de informações, estudos comparativos, bases de dados maiores e estrutura mais sólida de compartilhamento de conhecimento (Castells, 1999; Souza \& Quandt, 2008). Vale ressaltar que o presente estudo não inibe as discussões que contemplam a temática internacionalização de microempresas e pequenas empresas, com atenção em pesquisas brasileiras com análises, pois foi identificada vasta deficiência de estudos sobre esse tema. Como contribuição para o fortalecimento dos estudos brasileiros sobre MPEs, esse artigo traz opiniões formadas a partir da análise de estudos publicados em periódicos brasileiros.

\section{CONSIDERAÇÕES FINAIS}

O objetivo deste estudo foi analisar, de forma integrativa e sistemática, as contribuições em periódicos brasileiros que abordam os temas "internacionalização de MPEs", publicados na plataforma CAPES, sem período temporal e que trariam algum benefício para empresas que desejam iniciar um processo de internacionalização. A partir disso, foram encontrados trinta e quatro artigos na Plataforma CAPES sem período temporal e categorizados por semelhanças temáticas.

Conclui-se que as principais contribuições foram de estudos de casos de empresas, vantagens e desvantagens, processo de internacionalização e revisão teórica (Rocha et al., 
2010; Cislaghi, Fernandes \& Wegner, 2017; Rosa, Mello \& Ferreira, 2018; Araújo, Silva \& Cardoso, 2018; Ribeiro, 2016; Bellucci, Lavarda \& Roczanski, 2019; Lara \& Verdu, 2017).

A temática que prevalece são os casos de empresas que relatam o processo de internacionalização especificamente da empresa analisada. Já a revisão teórica nessa área é escassa. Outro grupo de destaque são as vantagens e desvantagens da internacionalização, trazendo um conceito geral do tema; o mesmo acontece com os artigos voltados ao processo de internacionalização que, apesar da sua relevância, não podem ser considerados como ponto seguro de informação para uma empresa iniciar seu processo de internacionalização dada as especificidades presentes em cada organização.

Dessa forma, este estudo contribuiu para o desenvolvimento da pesquisa e da ciência nacional na área de internacionalização de MPEs, permitindo uma análise geral e crítica das publicações em periódicos para que, assim, seja mais provável identificar possíveis falhas e temáticas com problemas de exploração e, desse modo, dar continuidade às temáticas desses estudos, bem como observar novas lacunas de pesquisa visando alavancar as pesquisas.

Vale ressaltar que as dificuldades encontradas para a realização do presente estudo se dão pela falta de artigos publicados na área de Administração e internacionalização de MPEs, não possuindo padrão específico ou caminho a ser seguido por aqueles que desejam adotar esse processo. Além disso, a pesquisa limitou-se a estudos com periódicos presentes na Plataforma CAPES, com strings restritos que possuíam critérios de exclusão. Observou-se também a pouca conectividade na rede de relacionamento dos autores e suas respectivas IES's, afetando também a interatividade entre diferentes regiões do Brasil.

Por fim, este artigo apresenta sugestões de estudos futuros, com vista a contribuir para a melhor compreensão do fenômeno e o oferecimento de informações sólidas às empresas que buscam essa estratégia futuramente, independentemente de sua classificação.

\section{REFERÊNCIAS}

Aaker, D. A. (2001). Administração Estratégica de Mercado. 5ed. Porto Alegre: Bookman Editora.

Anand, B. (2015). Reverse globalization by internationalization of SME's: opportunities and challenges ahead. Procedia-Social and Behavioral Sciences, 195, 1003-1011.

Araújo, J. G., Silva, L. V. B., \& Cardoso da Silva, M. E. P. (2018). Pequeñas empresas y las prácticas gerenciales: contribuciones a partir de la observación de las revistas brasileñas. Estudios Gerenciales, 34(149), 457-468.

Bardin, L. (2011). Análise de conteúdo. São Paulo: Edições 70.

Barki, E., Botelho, D., \& Parente, J. (2013). Varejo: desafios e oportunidades em mercados emergentes. Revista de Administração de Empresas, 53(6), 534-538.

Bellucci, C. F., Lavarda, R. B., \& Roczanski, C. R. M. (2019). A prática estratégica de pesquisa de mercado no processo de internacionalização de uma pequena cervejaria do sul do Brasil. Revista de Empreendedorismo e Gestão de Pequenas Empresas, 8(1), 24-51.

Boone, L. E., Kurtz, D. L. (1998). Contemporary Marketing wired. 9a ed. The Dryden Press. 
Jhenifer Andressa Da Cruz Barreto, Mariane Aparecida De Braz Bezerra, Marco Antonio Catussi Paschoalotto, Gustavo Yuho Endo e Érika Mayumi Kato Cruz

Canello, J. (2021). Mimetic isomorphism, offshore outsourcing and backshoring decisions among micro and small enterprises. Regional Studies, 1-18.

Cassanego Jr., P.; Ribeiro, N. S. (2010). Strategic behavior of the accommodation services sector in the tourism industry: analysis of the Fronteira da Paz conurbation. Estudios y Perspectivas em Turismo, 19.

Cassol, A., Novakowski, B. F. D., Tonial, G., \& Dalbosco, I. B. (2017). Estratégias de internacionalização de pequenas e médias empresas: estudo multicasos. Revista Gestão Organizacional, 10(3).

Castells, M. (1999). A sociedade em rede. São Paulo: Paz e Terra.

Cislaghi, T. P., Fernandes, E. B., \& Wegner, D. (2017). O Processo de Internacionalização na Transformação das Capacidades Dinâmicas de Pequenas Empresas. Revista de Empreendedorismo e Gestão de Pequenas Empresas, 6(3), 584-615.

Cooper, D. R.; Schindler; P. S. (2006). Business research methods (8th ed.). McGraw Hill.

Dal-Sato, F., Alves, J. N., Bulé, A. E., \& do Amarante, C. C. (2015). O processo de internacionalização da empresa de software TOTVS sob a ótica da abordagem comportamental. REGE-Revista de Gestão, 22(4), 493-508.

Domingues, L. M., Muritiba, P. M., \& Muritiba, S. N. (2016). Boa governança corporativa em micro e pequenas empresas leva à internacionalização? Contextus - Revista Contemporânea de Economia e Gestão, 14(3), 53-78.

Eriksson K., Johanson J., Majkgård A., \& Sharma D.D. (2015) Experiential knowledge and cost in the internationalization process. In: Forsgren M., Holm U., Johanson J. (eds) Knowledge, Networks and Power. Palgrave Macmillan, London. https://doi.org/10.1057/9781137508829_2

Fiates, G. G. S., Martins, C., Fiates, J. E. A., Martignago, G., \& dos Santos, N. (2013). Análise do papel da incubadora na internacionalização de empresas de base tecnológica, incubadas e graduadas. Revista Eletrônica de Estratégia \& Negócios, 6(1), 252-274.

Floriani, D. E., \& Fleury, M. T. (2012). O efeito do grau de internacionalização nas competências internacionais e no desempenho financeiro da PME brasileira. Revista de Administração Contemporânea, 16, 438-458.

Freitas, E. M. S., Rupolo, M., \& Oliveira, B. R. B. (2014). Processo de internacionalização de uma empresa do Vale do São Francisco: Influência dos agentes externos e das escolhas gerenciais. Organicom, 11(21), 144-163.

Garcia, S. F. A., Lima, G. B., \& de Carvalho, D. T. (2010). Redes interorganizacionais de cooperação para a internacionalização. REGE- Revista de Gestão, 17(2), 209-224. 
Gatti Jr, W., \& Marietto, M. L. (2017). Como pode um peixe vivo viver fora do Brasil? O caso Peixonauta. Revista Ibero Americana de Estratégia, 16(4), 110-116.

Gonçalves, R. (1999). Globalização e desnacionalização. São Paulo: Paz e Terra.

Greenhalgh, T. (1997). Papers that summarize other papers (systematic review and metaanalyses). British Medical Journal, 315(7109), 672-675.

Herranz, A., \& Machado, H. P. V. (2019). Motivadores da Internacionalização de Pequenas Empresas de Software: um estudo multi casos nos contextos brasileiro e espanhol. RECADM, 18(2), 261-280.

Jabbour, C. J. C., Santos, F. C. A., \& Barbieri, J. C. (2008). Gestão ambiental empresarial: um levantamento da produção científica brasileira divulgada em periódicos da área de administração entre 1996 e 2005. Revista de Administração Contemporânea, 12(3), 689-715.

Johanson, J., \& Wiedersheim-Paul, F. (1975). The internationalization of the firm: Four Swedish cases. Journal of Management Studies, 12(3), 305-322.

Kazungu, I. (2020). Network linkages and performance of exporting micro and small enterprises in Dar Es Salaam, Tanzania: Perspectives in the handicraft industry. Global Business Review, 0972150920934433.

Keegan, W. J. (2002). Global marketing management. New Jersey: Pearson Education Inc.

Kotabe, M., \& Helsen, C. (1998). Global marketing management. New York: John Wiley \& Sons Inc.

Kotler, P., \& Keller, K. L. (2006). Administração de Marketing (12a ed.). São Paulo: Pearson Pren-tice Hall.

Krakawer, P. V. C., Jussani, A. C., \& Vasconcellos, E. P. G. (2013). A utilização de alianças estratégicas na internacionalização de pequenas e médias empresas: estudo de caso em uma empresa brasileira de tecnologia da informação. REGE-Revista de Gestão, 20(3), 299-311.

Kubíčková, L., Votoupalová, M., \& Toulová, M. (2014). Key motives for internationalization process of small and medium-sized enterprises. Procedia Economics and Finance, 12, 319-328.

Lakatos, E. M., \& Marconi, M. A. (2001). Fundamentos metodologia científica (4a ed.). São Paulo: Atlas.

Lara, L. S. M., \& Verdu, F. C. (2017). A internacionalizacao das médias empresas brasileiras. Acta Scientiarum. Human and Social Sciences, 39(3), 245-257. 
Jhenifer Andressa Da Cruz Barreto, Mariane Aparecida De Braz Bezerra, Marco Antonio Catussi Paschoalotto, Gustavo Yuho Endo e Érika Mayumi Kato Cruz

Leite, Y. V. P., \& Moraes, W. F. A. D. (2015). A capacidade de inovar no empreendedorismo internacional. Revista de Administração, 50(4), 447-459.

Leite, Y. V. P., \& Moraes, W. F. A. D. (2014). Facetas do risco no empreendedorismo internacional. Revista de Administração Contemporânea, 18, 96-117.

Leone, N. M. D. C. P. (1991). A dimensão física das pequenas e médias empresas (PME'S): à procura de um critério homogeneizador. Revista de Administração de Empresas, 31, 53-59.

Lima, G. B., \& de Carvalho, D. T. (2011). Internacionalização de empresas em clusters industriais: um estudo aplicado no polo médico-hospitalar-odontológico de Ribeirão Preto-SP. REGE Revista de Gestão, 18(1), 19-33.

Lima, G. B., Neves, M. F., Thomé, L., \& de Carvalho, D. T. (2008). Consorcio de exportação como alternativa de pequenas e medias empresas: um estudo de caso na cadeia têxtil. REGE Revista de Gestão, 15(2), 1-18.

Martinelli, D. P., Ventura, C. A. A., \& Machado, J. R. (2004). Negociação Internacional. São Paulo: Editora Atlas.

Matta, J. R. N., \& Mello, R. D. C. (2014). A internacionalização de uma empresa brasileira de software de segurança à luz das teorias de redes e effectuation. Internext, 9(3), 78-94.

Mello, R. C., \& da Rocha, A. (2008). Casos de Ensino em Administração. RAC-Revista de Administração Contemporânea, 12(1), 231-252.

Minervini, N. (2008). O exportador: ferramentas para atuar com sucesso no mercado internacional (5a ed.). São Paulo: Pearson Prentice Hall.

MRE. Ministério das Relações Exteriores. (2011). Exportação Passo a Passo. Brasil, Brasília: MRE, $268 \mathrm{p}$.

Porter, M. E. (1989). Vantagem competitiva: criando e sustentando um desempenho superior. Rio de Janeiro: Campus Elsevier.

Porto, P., \& Mello, R. C. (2015). Empreendedorismo internacional e effectuation: o caso do café Yaguara Ecológico. Revista Eletrônica de Negócios Internacionais (Internext), 10(3), 15-30.

Ribeiro, F. F., Oliveira Jr, M. M., \& Borini, F. M. (2012). Internacionalização acelerada de empresas de base tecnológica: o caso das Born Globals brasileiras. Revista de Administração Contemporânea, 16, 866-888.

Ribeiro, H. C. M. (2016). Produção acadêmica do tema internacionalização divulgada nos periódicos nacionais: Um estudo bibliométrico. Internext, 11(1), 1-20. 
Rocha, A. D., Mello, R. C. D., Maculan, A. M. D., \& Pacheco, H. F. (2010). Ivia: crescimento e internacionalização. Revista de Administração Contemporânea, 14, 1158-1170.

Rosa, F. M., de Mello, R. C., \& Ferreira, V. A. C. (2018). O fenômeno da internacionalização e as empresas scale-up: Uma revisão sistemática da literatura. Revista Eletrônica de Negócios Internacionais: Internext, 13(2), 71-85.

Rosa, P. R., \& Rhoden, M. I. S. (2007). Internacionalização de uma empresa brasileira: um estudo de caso. REAd-Revista Eletrônica de Administração, 13(3), 684-704.

Ruzzier, M., Hisrich, R. D., \& Antoncic, B. (2006). SME internationalization research: past, present, and future. Journal of Small Business and Enterprise Development, 13(4), 476497.

Sarmento, C. F. B., Carvalho, C. A. S., \& Dib, L. A. R. (2016). Effectuation e a influência das redes sociais em internacionalização de startups em aceleradoras. Internext, 11(1), 6376.

Santos, L. B. (2016). Origem, consolidação e internacionalização dos grupos Mexichem e Tigre. Investigaciones Geográficas, Boletín del Instituto de Geografía, 2016(89), 121136.

Serviço Brasileiro de Apoio à Micro e Pequenas Empresas (Sebrae). Critérios de classificação do porte da empresa, 2017.

https://www.sebrae.com.br/sites/PortalSebrae/ufs/sp/sebraeaz/pequenos-negociosem-numeros,12e8794363447510VgnVCM1000004c00210aRCRD.

Silva, C. P., Paschoalotto, M. A. C., \& Endo, G. Y. (2020). Liderança organizacional: uma revisão integrativa brasileira. Revista Pensamento Contemporâneo em Administração, 14(1), 146-159.

Silva, R. A., \& Moraes, W. F. A. (2013). A evolução do modelo de uppsala à luz da abordagem dos sistemas adaptativos complexos. Internext, 8(3), 63-80.

Silveira, F. F., Armellini, F., Aquino, L. N. D., \& Giroletti, D. A. (2012). A adoção da inovação aberta dentro da estratégia de internacionalização de empresas multinacionais de economias emergentes. Revista de Gestão e Projetos, 3(3), 251-276.

Souza, Q., \& Quandt, C. (2008). Metodologia de Análise de Redes Sociais. In: Duarte, F., Quandt, C., \& Souza, Q. (Org.). O Tempo das Redes. (pp. 31-63) São Paulo: Perspectiva.

Triviños, A. N. S. (1987). Introdução à pesquisa em ciências sociais: a pesquisa qualitativa em educação. São Paulo: Atlas.

Vianna, N. W. H., Melo, P. L. R., \& Ryngelblum, A. L. (2014). O processo decisório para internacionalização em redes de franquias brasileiras: um estudo de caso múltiplo. Internext, 9(1), 101-118. 
Jhenifer Andressa Da Cruz Barreto, Mariane Aparecida De Braz Bezerra, Marco Antonio Catussi Paschoalotto, Gustavo Yuho Endo e Érika Mayumi Kato Cruz

Zapata, L. F. B., \& Barrientos, S. C. A. (2013). Retos de gestión intercultural en las actividades de internacionalización de microempresas de Medellín. Estudios Gerenciales, 29(129), 456-465.

Zen, A. C. (2012). O processo de internacionalização e o impacto nos recursos da firma: o caso da vinícola Casa Valduga. Internext, 7(1), 123-148.

Zonatto, P. A. F., Sbissa, A. P., Teston, S. F., \& Zonatto, V. C. S. (2017). Chegou a hora? O processo de sucessão de uma pequena empresa familiar. Revista Gestão Organizacional, 10(2), 66-79. 